\title{
CHARACTERISATION OF FLOW AND HEAT TRANSFER IN SINTERED METAL FOAMS
}

\author{
Jörg Sauerhering/German \\ Aerospace Center, Linder Höhe, \\ 51143 Köln, Germanyl \\ joerg.sauerhering@dlr.de
}

\author{
Stefanie Angel/Department of \\ Ferrous Metallurgy, Aachen \\ University, 52066 Aachen, \\ Germanylangel@iehk.de
}

\author{
Thomas Fend/German Aerospace \\ Center, Linder Höhe, 51143 Köln, \\ Germany/thomas.fend@dIr.de
}

\author{
Stefan Brendelbergerl German Aerospace Center, \\ Linder Höhe, 51143 Köln, \\ Germany/Stefan.brendelberger@dlr.de
}

\author{
Robert Pitz-Paal German Aerospace Center, Linder \\ Höhe, 51143 Köln, Germanyl \\ robert.pitz-paal@dlr.de
}

\author{
Elena Smirnova/German Aerospace Center, Linder \\ Höhe, 51143 Köln, Germanylolena.smirnova@dlr.de
}

\begin{abstract}
Since sintered metal foam is an innovative material with promising properties such as high porosity, good thermal conductivity, beneficial mechanical properties like strength and weldability, it has been considered to be applied as an open porous wall element in combustion chambers of gas turbines. In this application, the foam serves as a functional material capable to lead cooling air through micro- and minichannels into the inside of the combustion chamber. This cooling technique also known as effusion cooling keeps the combustion chamber walls below critical temperatures and therefore enables the burning process to be more effectively operated at higher temperatures. For a proper design of the wall element, the temperature distribution along the path of the fluid inside the foam must be known. For an exact calculation of the temperature flow and heat transfer processes inside the foam must be known. Therefore in this study the permeability and heat transfer properties of the foam have been characterized experimentally. The methods are described and the results in terms of permeability coefficients, convective heat transfer coefficients and effective thermal conductivity are presented as functions of the foam's porosity. The method of the calculation is described and finally, the results of the calculation are presented, showing that due to the fine grained structure of the foam, the heat transfer from the solid to the cooling fluid takes place in a thin layer close to the inner surface of the camber wall.
\end{abstract}

\section{INTRODUCTION}

The efficiency of state-of-the-art combined cycle power plants is limited to approximately $58 \%$ due to limited temperature and corrosion stability of the applied materials. To achieve higher efficiencies a number of research activities are carried out. One concept to achieve higher gas turbine temperatures and thus higher efficiencies is to actively cool the combustion chamber wall of the gas turbine by the so called effusion cooling. The concept foresees open porous wall elements through which cooling air is blown into the combustion chamber. This concept is investigated in a collaborative research activity at Aachen University, The Jülich Research Center and the German Aerospace Center called "Thermally Highly Loaded, Porous and Cooled Multi-Layer Systems for Combined Cycle Power Plants". Together with further concepts dealing with gas turbine blade improvement and improvement of the connected steam turbine, the efficiency of the combined cycle is aimed to be increased to approximately $65 \%$. For further information see Bohn and Moritz (2001) and Bohn (2002). The principle of effusion cooling is illustrated in Fig. 1. As an open porous material for the wall element a metal foam has been developed in the past years in the Institute of Ferrous Metallurgy, one of the members of the SFB 561. As can be seen in Fig. 1, the metallic foam is intended to be coated with a thermal barrier layer with laser drilled boreholes. However the coating as well as the holes are 
not the matter of this study, which deals with the characterization of the heat and mass transfer of the foam. A metal foam has been chosen because of its easy way to be manufactured, its good thermal properties and its good mechanical properties. Finally, it has also been found out, that the foam may easily connected by welding to the load bearing metallic structure of the chamber wall (Longerich et al. 2007). The knowledge of the temperature distribution inside the wall element (foam+coating) is important to predict the lifetime of the materials employed. To predict the temperature, heat transfer characteristics as well as flow through the foam has to be characterized. For this, experimental data on the convective heat transfer characteristics, the thermal conductivity and the pressure drop characteristics is needed. Both, temperature prediction and determination of quantities is object of the present study.

\section{NOMENCLATURE}

$\begin{array}{lll}\mathrm{A}_{\mathrm{V}} & \text { Surface to volume ratio } & \mathrm{m}^{-1} \\ \mathrm{~A} & \text { Cross-section (of a sample) } & \mathrm{m}^{2} \\ \mathrm{C}_{\mathrm{PF}} & \text { Heat capacity of the fluid } & \mathrm{Jkg}^{-1} \mathrm{~K}^{-1} \\ \mathrm{~d} & \text { Hydraulic (characteristic) diameter } \mathrm{m} & \mathrm{m} \\ \mathrm{K}_{1} & \text { Viscosity Coefficient } & \mathrm{m} \\ \mathrm{K}_{2} & \text { Inertial Coefficient } & \mathrm{m} \\ \mathrm{L} & \text { Length x-direction } & \mathrm{kg} \cdot \mathrm{s}^{-2} \cdot \mathrm{m}^{-2} \\ \dot{m} & \text { Mass flow density } & \mathrm{kgs} \\ \dot{M} & \text { Mass flow } & - \\ \mathrm{Nu} & \text { Nußelt-number } & \mathrm{Pa} \\ \mathrm{p} & \text { Pressure } & \mathrm{W} \\ \dot{Q} & \text { Heat flux } & \mathrm{W} \cdot \mathrm{m}^{-3} \\ \dot{q} & \text { Heat flux per volume } & - \\ \mathrm{Re} & \text { Reynolds-number } & \mathrm{K} \\ \mathrm{T}_{\mathrm{S}} & \text { Temperature of solid phase } & \mathrm{K} \\ \mathrm{T}_{\mathrm{F}} & \text { Temperature of the fluid phase } & \mathrm{K} \\ \mathrm{T}_{0} & \text { Ambient temperature } & \\ \mathrm{t} & \text { Time [s] } & \mathrm{m} \cdot \mathrm{s}^{-1} \\ \mathrm{U}_{0} & \text { Fluid Velocity } & \mathrm{m} \\ \mathrm{V} & \text { Volume } & \mathrm{m} \\ \mathrm{X} & \text { Direction of the main flow }\end{array}$

$\begin{array}{lll}\alpha & \text { Heat transfer coefficient } & \mathrm{Wm}^{-2} \mathrm{~K}^{-1} 1 \\ \varepsilon & \text { Total porosity } & - \\ \varepsilon^{*} & \text { Primary porosity } & \\ \mu_{\text {DYN }} & \text { Fluid Dynamic Viscosity } & \mathrm{Pa} \cdot \mathrm{s} \\ \lambda_{\text {fluid }} & \text { Heat conductivity of the fluid } & \mathrm{Wm} \mathrm{K}^{-1} \\ \lambda_{\text {eff }} & \text { Effective heat conductivity } & \mathrm{Wm}^{-1} \mathrm{~K}^{-1} \\ \rho_{\mathrm{F}} & \text { Density of the fluid } & \mathrm{gcm}^{-3} \\ \rho_{\text {FOAM }} & \text { Density of the foam } & \mathrm{gcm}^{-3} \\ \rho_{\text {MATRIX }} & \text { Density of the matrix material } & \mathrm{gcm}^{-3}\end{array}$

\section{INVESTIGATED MATERIALS}

The foams reported of in the present study are produced by the SlipReactionFoamSintering (SRFS)-process. This is a method to produce metallic foams with an open, porous cell structure by a chemical reaction process. As this foaming is a rather new method there is not yet ready available data concerning the pore structure or the behavior to fluid flow. There are well known foams manufactured by metal deposition on cellular preforms like polyurethane foams or by casting using a polymer precursor as template (Ashby et al., 2000). Compared to these foams the foams investigated in the present study are much less regular due to a much thinner distribution of gas bubbles in the liquid slip. Therefore it was necessary to conduct a series of extensive experiments in order to characterize the SRFS foams. A first introduction and first results have been previously published by Reutter et al. (2006). The investigated samples for this study are made of Hastelloy B, Inconel 625 and NCpowder. The grain sizes range between 50 and $150 \mu \mathrm{m}$. The iron based samples (NC) were sintered at $1170^{\circ} \mathrm{C}$, the nickel based samples (Inconel 625 and Hastelloy B) at $1200^{\circ} \mathrm{C}$. After evacuating the furnace one time before starting the sintering process, the samples were sintered under a reducing atmosphere of $100 \% \mathrm{H}_{2}$.

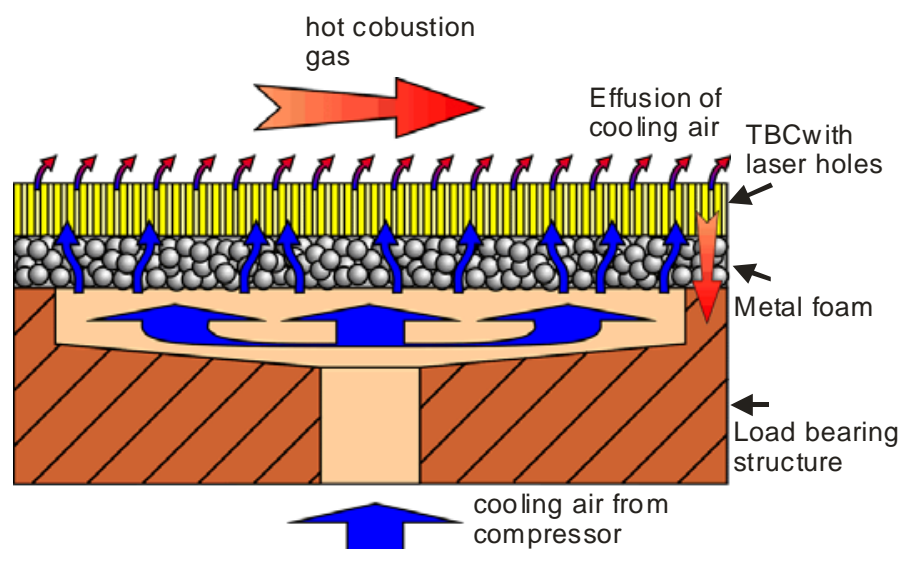

Figure 1: Gas turbine combustion chamber effusion cooling principle (sketch courtesy of IDG, Aachen Technical University)

Samples made only of the sintered slip without foaming show a porosity of about $50 \%$ (densities of $3.8-4.2 \mathrm{~g} / \mathrm{cm}^{3}$ ) and are called sintered powder samples or matrix material. In comparison to these, the dense metals have densities of 7.87 $\mathrm{g} / \mathrm{cm}^{3}$ (NC), $9.24 \mathrm{~g} / \mathrm{cm}^{3}$ (Hastelloy B) and $8.44 \mathrm{~g} / \mathrm{cm}^{3}$ (Inconel 625). The sintered powder samples are taken as representing the material of the pore walls in the foams. The foams have a total porosity between 62 and $87 \%$ (densities of $1.2-3.7$ $\left.\mathrm{g} / \mathrm{cm}^{3}\right)$. The pores can be characterized as those which arise from the hydrogen foaming, called the primary pores, and those which are the spaces between adjacent grains of the sintered powder, called the secondary pores (Angel et al., 2004). The secondary pores reach up to $0.3 \mathrm{~mm}$ diameter and the primary pores reach up to $3.5 \mathrm{~mm}$. Since for a number of physical phenomena only the primary porosity is of interest, it may be determined from the density of the foamed sample $\rho_{\text {FOAM }}$ and the density of the matrix material $\rho_{\text {MATRIX: }}$ 


$$
\varepsilon^{*}=\left(1-\frac{\rho_{F O A M}}{\rho_{\text {MATRIX }}}\right) \text {. }
$$

It is only possible to determine the two different pore types indirectly. From a foamed sample of e.g. $75 \%$ total porosity we know that All densities were determined as gravimetrical densities by weighing the foam samples and dividing this weight by the total volume of the foam sample. The total porosity was determined by using the density of the bulk material as the reference. The samples were manufactured at the Department of Ferrous Metallurgy at Aachen University. The samples are cylinders with diameters between 64 and 81 $\mathrm{mm}$ and the length was between 9 and $30 \mathrm{~mm}$. The picture of a typical sample can be seen in Figure 2 (right) together with an optical micrograph of the sample (left). For measurements of anisotropy effects of the permeability cubical samples were used with $45 \mathrm{~mm}$ side length.

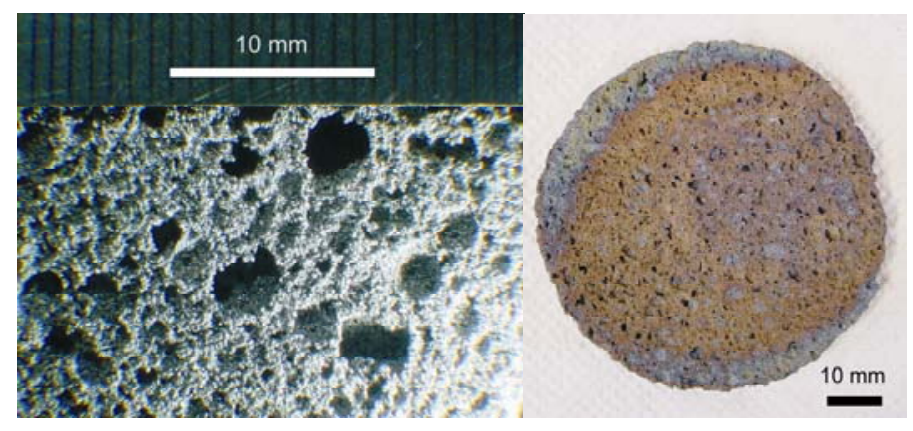

Figure 2: Picture of a sample of a Hastelloy B foam (right) and a detailed view of the pore structure (left)

\section{EXPERIMENTALLY ACQUIRED MATERIAL DATA}

\section{Effective Heat Conductivity}

Unlike for a solid material for the porous foam, heat conductivity $\lambda_{\mathrm{EFF}}$ is considered to be a "volume averaged effective quantity". For this study, this quantity has been determined with the Transient Heat Source Technique also called "Hot Disk". This technique has been applied as if the foam would have been a simple solid material. The technique has been chosen, because the tested volume of approximately $2-4 \mathrm{~cm}^{3}$ is relatively large compared to the Laser Flash method e.g. This large tested volume justifies the assumption, that $\lambda$ is a "volume averaged quantity", which comprises all the micromechanisms, which are conductive heat transfer in the grains, convective heat transfer in the pores and radiation heat transfer from one pore wall to another. The microstructure including the pore distribution within the tested volume has then been taken as representative for the testes material. Basics of the experimental set-up have been reported previously (Fend, 2005). The Inconel material without primary pores has been additionally measured with the Laser Flash method for comparison. This material was the only one, which could be tested with the Laser Flash method, because it was possible to have a characteristic volume within the relatively small size of tested volume $(\varnothing 10 \mathrm{~mm} * 3 \mathrm{~mm}$ length). It shows values of $\lambda_{\mathrm{EFF}}=0.87 \mathrm{~W} / \mathrm{mK}$ at room temperature. This is only about $1 / 10$ of the thermal conductivity of the dense metal $(\lambda=9.1 \mathrm{~W} / \mathrm{mK}$ at $25^{\circ} \mathrm{C}$ ). The heat conductivity of the foams with primary pores is even lower. Results from room temperature measurement of the effective thermal conductivity of three different materials are shown in Fig. 3. For each kind of material, a variety of samples with different primary porosities were investigated.

In the graph, the effective thermal conductivity has been normalized with the thermal conductivity of air $\left(\lambda_{\text {fluid }}=0,026\right.$ $\mathrm{W} / \mathrm{mK}$ ) for a better comparison of the data. Pure matrix materials without primary porosity appear on the left side.

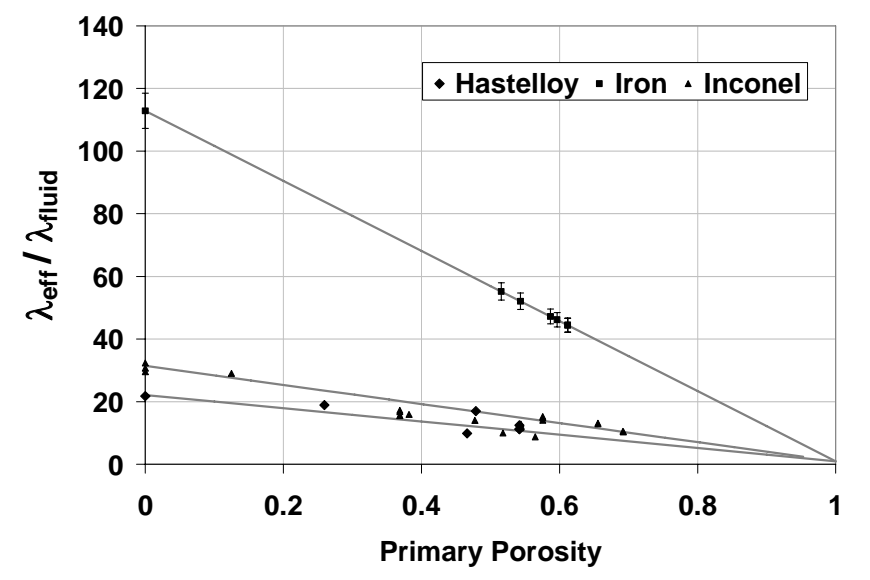

Figure 3: Relative effective thermal conductivity of Inconel, Hastelloy and Iron foams as a function of their primary porosity

A simple rule of mixture holds, if only the primary porosity $\varepsilon^{*}$ is considered:

$$
\lambda_{\text {FOAM }}=\varepsilon^{*} \lambda_{\text {FLUID }}+\left(1-\varepsilon^{*}\right) \cdot \lambda_{\text {MATRIX }}
$$

The matrix thermal conductivity itself may be explained with models similar to those having been developed for packed beds (Sauerhering et al., 2006). These models generally assume identical particles connected to each other with bars of a certain cross-section. By varying the length and cross-section of the bars, experimental data may be matched in a proper way. 


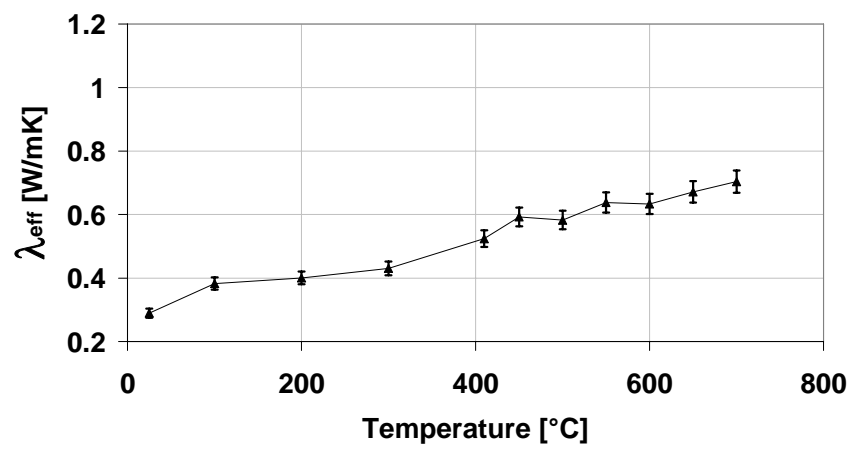

Figure 4: Effective thermal conductivity of the Inconel matrix material as a function of temperature.

In Fig. 4, the high temperature thermal conductivity values of a selected Inconel material are shown. Temperature increase is similar to that of the dense metal.

\section{Convective Heat Transfer Coefficients}

Also the effective volumetric heat transfer coefficient $\alpha A_{V}$ is considered as a volume averaged quantity describing the solid to fluid heat transfer inside the porous material. Here $\alpha$ denotes the well known convective heat transfer coefficient from the equation

$\dot{Q}=\alpha A \cdot\left(T_{S}-T_{F}\right)$

in which the heat flow $\dot{Q}$ may be approximated by multiplying the heat transfer coefficient $\alpha$ with the participating heattransfer surface A and the fluid/solid temperature difference. Considering an infinitesimal volume element, equation (2) transfers to

$$
\dot{q}=\alpha A_{V} \cdot\left(T_{S}-T_{F}\right)
$$

with $A_{V}=\mathrm{A} / \mathrm{V}$, the specific surface area participating in convective heat transfer usually measured in $\mathrm{m}^{2} / \mathrm{m}^{3}$ derived from the total inner surface area of the open porosity and the sample volume v. This expression also appears as heat source expressions in the general heat balance equations (5) and (6) of the solid and the fluid phase.

The values of $\alpha A_{V}$ from a number of different foam materials have been determined with a transient method after Viskanta and Younis (1993). An air flow of alternating temperature is directed through a porous sample, which causes an amplitude decrease of the temperature wave (Fig. 5). From this, $\alpha A_{V}$ may be determined.
Making use of the similarity theory, from $\alpha A_{V}$ more general Nusselt numbers $(\mathrm{Nu})$ may be determined $\left(N u=\alpha d / \lambda_{\text {FLUID }}\right)$. For this, a characteristic channel diameter $d$ is needed, furthermore, the thermal conductivity of the fluid $\lambda_{\text {FLUID }}$. For those materials, of which the results are shown in Fig 6, this diameter has been determined to approximately $0.5 \mathrm{~mm}$ by experiments observing the capillary flow of water into the pores. In fact this quantity may be considered as a mean pore diameter averaging the large range of pore diameters from 0.2 to approximately $3.5 \mathrm{~mm}$. Instead, a pore size distribution would be more useful to work with in case of numerical calculations. However, the present approach aims at finding a model for the volumetric convective heat transfer, which comprises average values all over the total sample volume. Reynolds numbers have been calculated from fluid flow velocity $U_{0}$ and fluid viscosity $\eta$ by $R e=d U_{0} / \eta$. The results show, that the heat transfer increases with decreasing porosity. Imagining the pore structure as set of $\varnothing 0.5 \mathrm{~mm}$ channels, a rough approximation of the specific surface $A_{V}$ may be undertaken and Nusselt numbers may be determined directly. For the shown Hastelloy materials Nusselt numbers of $2.5<\mathrm{Nu}<5$ were calculated. These values fit well to the empirical equations for the case of laminar flow inside a tube, which give $\mathrm{Nu}$ numbers of $\mathrm{Nu} \approx 3.7$.

\section{Permeability}

Permeability of the foam was simply investigated by generating an air flow of various fluid velocities through the foam samples and measuring the pressure difference of the fluid before and behind the sample according to Fig. 7.
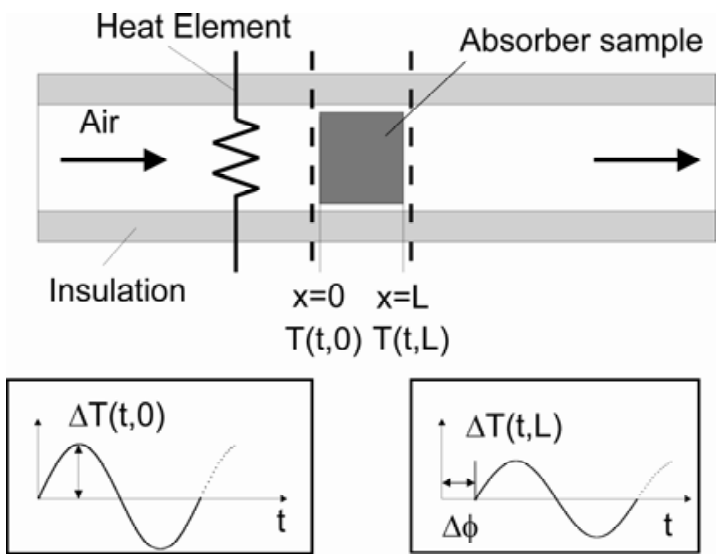

Figure 5: Principle of the set-up used for the convective heat transfer coefficient measurements, in the lower graphs the fluid temperature is shown schematically as a function of time 

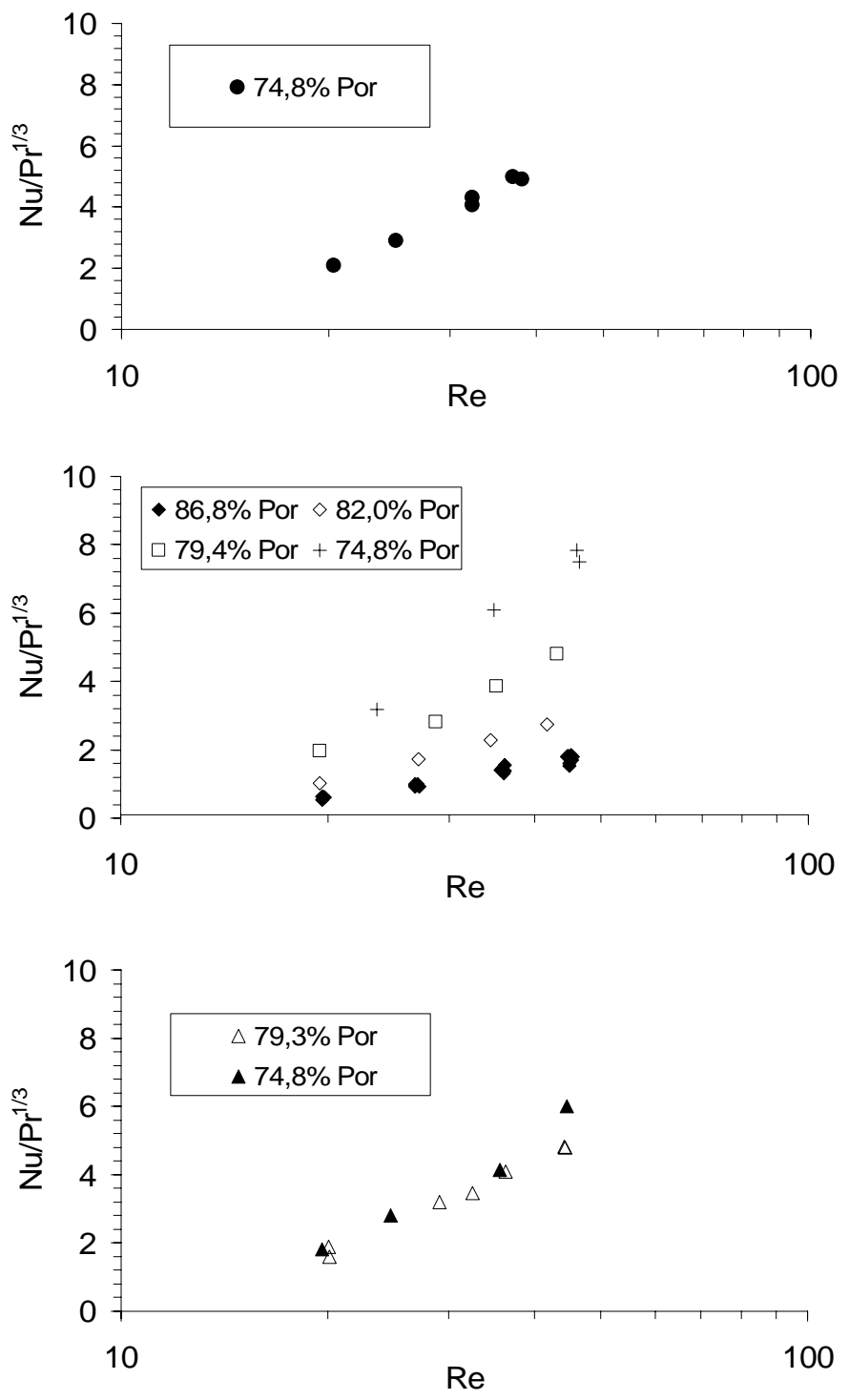

Figure 6: Nusselt-Prandtl/Reynolds plots derived from volumetric convective heat transfer measurements with metal foams of different porosity.

Pressure loss/air velocity plots were generated as can be seen in Fig. 8. The plots were fitted with the extended Darcy equation

$$
\frac{\Delta p}{L}=\frac{\mu_{D Y N}}{K_{1}} U_{0}+\frac{\rho_{F}}{K_{2}} U_{0}^{2}
$$

in which $\Delta p$ denotes pressure difference, $L$ the length of the sample in the direction of flow, $\mu_{D Y N}, \rho_{F}$ and $U_{0}$ the dynamic viscosity, the density and the velocity of the fluid respectively. From the plots and the fluid data, which is taken from standard tables, $K_{1}$ and $K_{2}$, the characteristic constants of the porous material are determined. Most frequently they are called the permeability and the inertial coefficient, because $K_{1}$ is the contribution of the viscous drag of the pores to permeability and $K_{2}$ the contribution of the acceleration of the fluid particles through the tortuous path of the flow through the material. The inertial coefficients determined are shown in Fig. 9 as a function of the total porosity of the foam samples. It can be clearly seen, that permeability increases significantly, when the porosity reaches approximately $70 \%$. The obvious conclusion, that the primary pores form a network of channels is not yet proved by metallographic investigations.

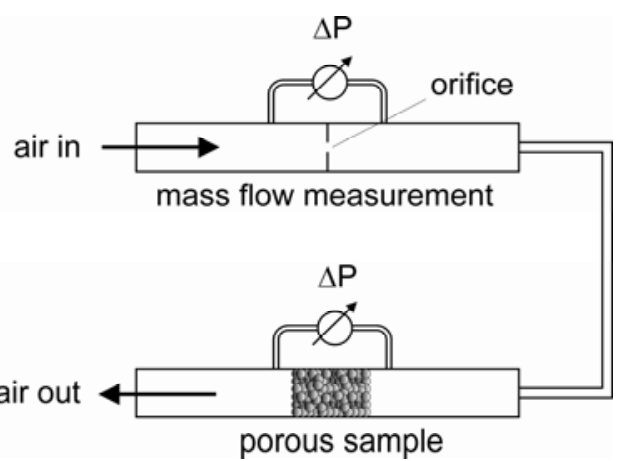

Figure 7: Set-up used to measure permeability of foams

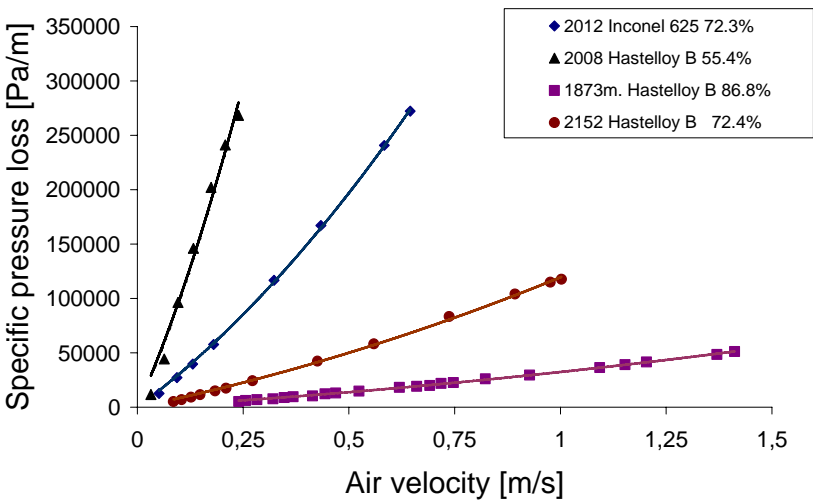

Figure 8: Pressure loss/Air velocity plots generated during permeability measurements

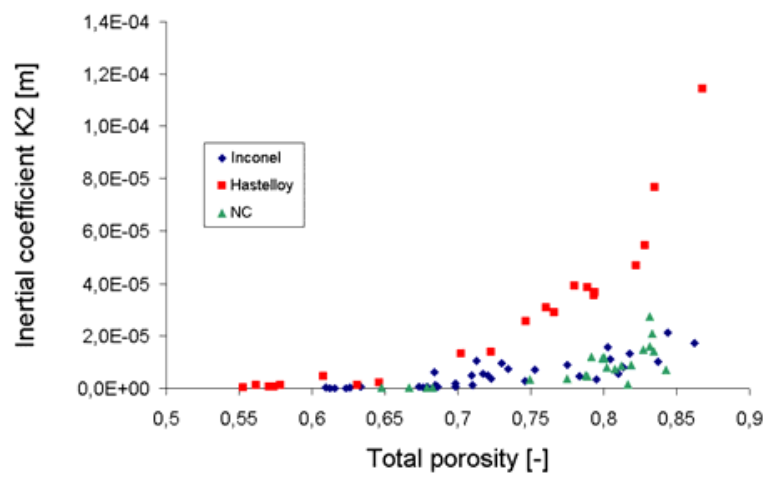

Figure 9: The inertial coefficient as function of the total porosity 
Additionally the question has been investigated, weather the process of manufacturing induces some anisotropy effects of the permeability. Therefore the pressure losses of cubic samples have been measured in 6 directions. The results are presented in Fig. 10. In two flow directions higher pressure losses could be observed. These directions are denoted with "from above" and "from below", indicating that these were the direction of the gravity forces and the opposite direction during the process of sintering and before. In this situation, the gravitational forces may induce a deformation of the gas bubbles, giving them an anisotropic shape with the consequence of an anisotropic permeability too. However, this assumption has not yet been proven by microscopic investigations.

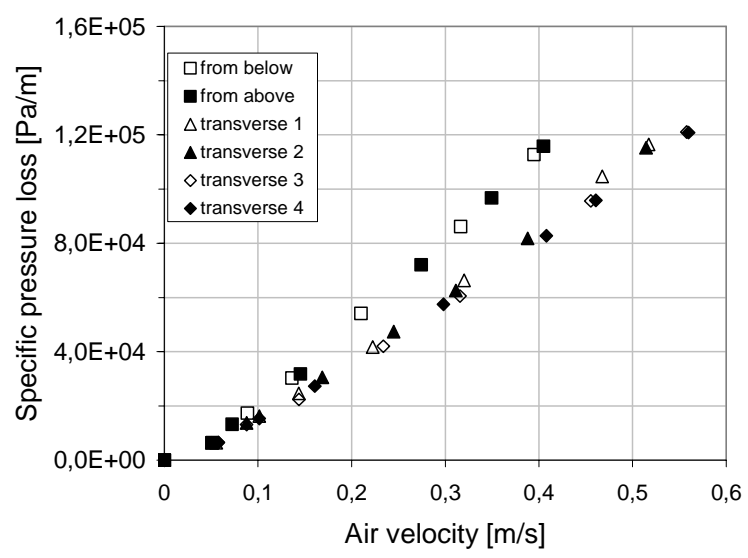

Figure 10: Pressure loss/air velocity plots from the measurement campaign investigating the anisotropy of the permeability

\section{Analytical Results}

Using the effective material data acquired in the chapters before, the heat flow balance equation for the solid and the fluid phase

$$
\begin{aligned}
& \lambda_{\text {eff }} \frac{d^{2} T_{S}}{d x^{2}}-\alpha A_{V}\left(T_{S}-T_{F}\right)=0 \\
& \dot{m} c_{P} \frac{d T_{F}}{d x}=-\alpha A_{v}\left(T_{S}-T_{F}\right)
\end{aligned}
$$

can be solved analytically as a system of differential equations. This one dimensional approach has been chosen as a first step assuming heat and fluid flow only in the direction perpendicular to the combustion chamber wall.

Two mass flow rates $\dot{m}=10 \mathrm{~kg} / \mathrm{m}^{2}$ and $\dot{m}=7 \mathrm{~kg} / \mathrm{m}^{2}$ have been compared under the assumption of a constant heat flow rate from the inside of the combustion chamber:

$\dot{q}=\lambda_{\text {eff }} \frac{d T_{S}}{d x}=1 \cdot 10^{6}\left[\frac{W}{m^{2}}\right]$
The result can be seen in Fig. 11. The bold lines belong to the higher mass flow rate. In both cases the surface temperature rapidly decreases, so that after $2 \mathrm{~mm}$ of foam already a constant temperature level is reached. Although the volumetric heat transfer coefficients turned out to be high, in the area close to the inside of the combustion chamber the temperature difference between the solid and fluid phase is approximately $400^{\circ}$. After that, this difference rapidly vanishes after a distance of approximately $2 \mathrm{~mm}$.

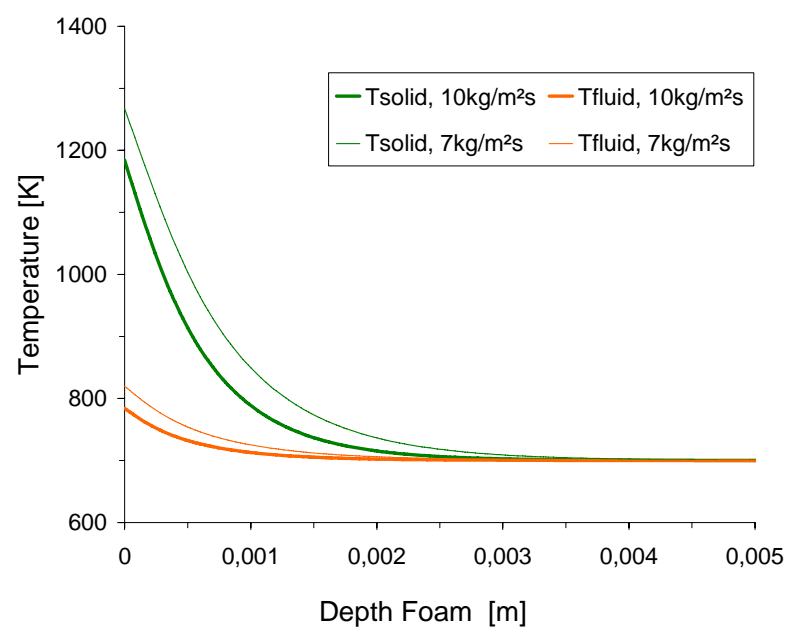

Figure 11: Fluid and solid temperature distribution inside the combustion chamber wall assuming a heat flux of $50 \mathrm{WM} / \mathrm{m}^{2}$ (1D analytical solution)

\section{CONCLUSIONS AND PROSPECTS}

The 1D-solution of the heat transfer equation is a first approach to describe the temperature distribution inside the porous combustion chamber wall. However, the presence of large pores of up to $3 \mathrm{~mm}$ diameter leads to deviations from symmetry of the temperature field and thus to a non-satisfying accuracy of the 1D approach. To also take into account the local effect of a primary pore on the temperature field, a $2 \mathrm{D}$ or $3 \mathrm{D}$ calculation is necessary. In this case the matrix material will be described as a homogenized continuum and the primary pores will be taken into account in a detailed structure analysis. Most probably, only limited volumes may then investigated. In this case it has to be regarded, that due to dissipation effects also the effective conductivity becomes anisotrope. It becomes larger in the direction perpendicular to the main flow direction. Moreover, this effect is dependent on the velocity of the fluid flow. At the moment an experimental technique to characterize the $\lambda_{\text {EFF }}$ with flow is under development. Furthermore, during the ongoing project an experimental validation of the temperature distribution inside the wall element (Fig. 11) is foreseen. 


\section{ACKNOWLEDGMENTS}

The work of the whole research center SFB561 has been funded by the German Research Foundation (DFG). This support is gratefully acknowledged.

\section{REFERENCES}

Angel, S., Bleck, W., Scholz, P.F., Fend, Th. 2004. "Influence of powder morphology and chemical composition on metallic foams produced by SlipReactionFoamSintering (SRFS)-process," Steel Research Int. 75, 483-488

Ashby, M.F., Evans, A., Fleck, N.A., Gibson, L.J., Hutchinson, J.W., Wadley, H.N.G. 2000. Metal Foams, a Design Guide, Butterworth Heinemann, pp. 11-14.

Bleck, W., 2007, Joining Strategies for Open Porous Metallic Foams on Iron and Nickel Base Materials. Advanced Engineering Materials, 2007. 9(8): p. 670-678.

Bohn, D. 2002. "New Materials and Cooling Systems for High Temperature, Highly Loaded Components in Advanced Combined Cycle Power Plants," presented at the 7th Liege Conference on Materials for Advanced Power Engineering, Sept. 30 - Oct. 02, 2002

Bohn, D., Moritz, N. 2001. "Numerical Investigation on Flow Field and Heat Transfer Phenomena in Multi-Hole Cooling Configurations" presented at the RTO-Symposium, May 2001

Fend, Th., Trimis, D., Pitz-Paal, R., Hoffschmidt, B., Reutter, O. 2005."Thermal Properties", in: M. Scheffler and P. Colombo: „Cellular Ceramics“, Wiley VCH.

Longerich, S., Piontek, D., Ohse, P., Harms, A., Dilthey, U., Angel, S., Reutter, O., Sauerhering, J., Smirnova, E., Fend, Th., Angel, S., PitzPaal, R. 2006. "Experimental Investigation of Heat Transfer and Pressure Drop in Porous Metal Foams," presented at the 4. ASME ICNMM, June 19-21, 2006

Sauerhering, J., Reutter, O., Fend, Th. Pitz-Paal, R., Angel, S. 2006 „Temperature Dependency of the Effective Thermal Conductivity of Nickel Based Metal," presented at the 4. ASME ICNMM, June 19-21, 2006

Viskanta, R., Younis, L.B. 1993. Int. J. Heat Mass Transfer, 36, 1425 1434 